\title{
Interpretation of Action Potential Generation Mechanism in Cardiomyocytes by Potassium Channel "Origami Windmill" Model
}

\author{
Zuodong Sun \\ Ya'ou Brain Science Institute of Heilongjiang province, Harbin 150090, China
}

\begin{abstract}
Abstrac:
The study of the action potential of cardiomyocytes is as important as the study of nerve fiber cells. The theoretical basis of the action potential of cardiomyocytes is the ionic theory formed by nerve fiber cells. Its core point of view: the decline phase of the action potential of cells is dominated by $\mathrm{K}^{+}$outflow. Applying the principle of the $\mathrm{K}^{+}$channel "origami windmill" model, the mechanism of action potential generation of nerve fiber cells has been reasonably explained, and a point contrary to the ion theory has been drawn: the phase of the action potential decline is dominated by $\mathrm{K}^{+}$influx. Similarly, applying the principle of the $\mathrm{K}^{+}$channel "origami windmill" model can also give a reasonable explanation for the mechanism of action potential generation of cardiomyocytes.

The difference between cardiomyocyte action potential and nerve fiber cell: In addition to $\mathrm{K}^{+}$, $\mathrm{Cl}^{-}, \mathrm{Na}^{+}$, the process of generating cardiomyocyte action potential also involves the participation of $\mathrm{Ca}^{2+} . \mathrm{Ca}^{2+}$ inflow in the rising phase will shorten the depolarization time; $\mathrm{Ca}^{2+}$ inflow in the falling phase will prolong the repolarization time. $\mathrm{K}^{+}, \mathrm{Ca}^{2+}$ space substitution proportion: rotate into $2 \mathrm{~K}^{+}$, squeeze out $3 \mathrm{Ca}^{2+}$, and 4 extra negative charges in the cell, the proportion is $2: 3: 4$; Conversely, squeeze out $2 \mathrm{~K}^{+}$, rotate into $3 \mathrm{Ca}^{2+}, 4$ extra positive charges the cells, the proportion is 3: 2: $4 . \mathrm{Na}^{+}, \mathrm{Ca}^{2+}$ space substitution proportion: rotate into $1 \mathrm{Na}^{+}$, squeeze out $1 \mathrm{Ca}^{2+}$, and 1 extra negative charges in the cell, the proportion is $1: 1: 1$; Conversely, rotate into $1 \mathrm{Ca}^{2+}$, squeeze out $1 \mathrm{Na}^{+}$, there is 1 more positive charge in the cell, and the proportion is 1: 1: 1 .

Application of "origami windmill" model principle, can reasonably explain the cardiomyocytes action potential generation mechanism, further proveding "origami windmill" the model theory, "the theory of dove-like particles"'the theory of braincell activation" of science, also proved that the viewpoint of "action potential descending phase, dominated by $\mathrm{K}^{+}$internal current" is correct. The scientific and rational interpretation of the action potential of cardiomyocytes has far-reaching impact and great significance to the basic theoretical research and clinical practice of the heart from now on.
\end{abstract}

Keywords: $\mathrm{K}^{+}$channel; "origami windmill” model; cardiomyocytes; action potential; generation mechanism

In 1879, Burdon-Sanderson and Page first recorded the action potential of myocardium using electrical instruments ${ }^{[1]}$. In 1936, Goldenberg and Rothberger recorded spontaneous electrical activity of dog Purkinje fibers ${ }^{[2,3]}$ (Figure 1). In 1949, in the United States, Woodbury, Woodbury and Hecht successfully recorded the

* Corresponding author: Zuodong Sun (E-mail: sunzuodong@pai314.com). 
resting potential and action potential of frog cardiomyocytes ${ }^{[4]}$; In the United Kingdom, Weidmann and Coraboeuf recorded intracellular electrical activity on the dog 's "pseudo-tendon"[5].

However, during the 140 years from 1879 to 2020 , no satisfactory explanation has been given for the mechanism of action potentials of cardiomyocytes. From 1879 to 1949, it was limited by the technical conditions at that time. After 1949, this problem has not been clearly explained, it is not just a technical problem. The existing theoretical basis of cardiomyocyte action potential is the ionic theory ${ }^{[6]}$ formed by nerve cells, and its core point of view: the phase of cell action potential decline is dominated by $\mathrm{K}^{+}$outflow. Application of ionic theory, it is impossible to elucidate the generation mechanism of action potential in nerve fiber cells, same thing it is also impossible to give a reasonable explanation of the generation mechanism of action potential in cardiomyocytes.

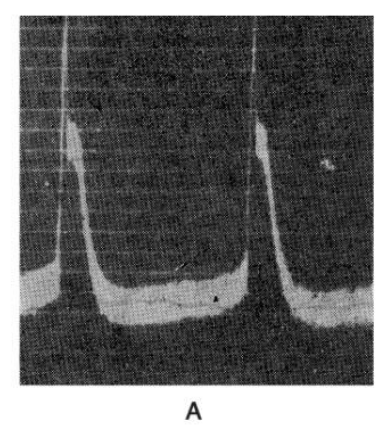

$\mathrm{mV}$
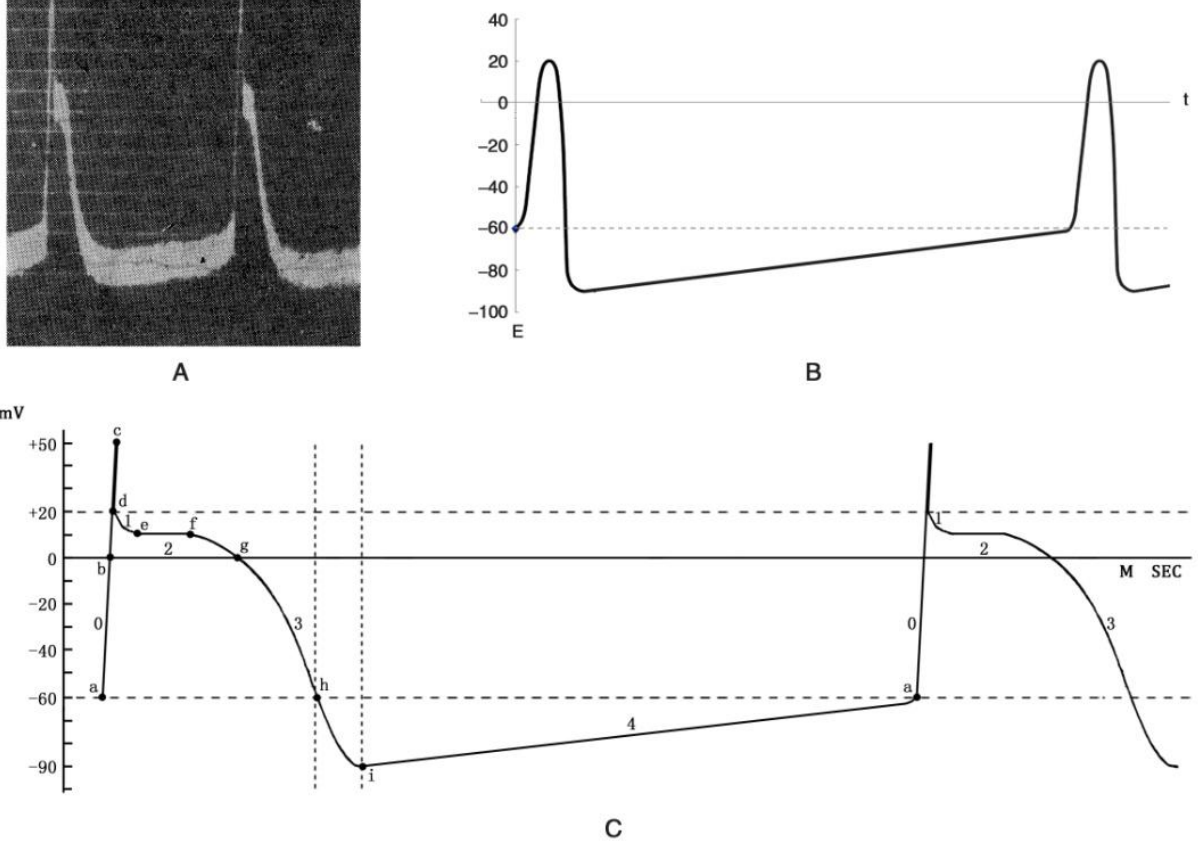

Figure 1 Dog "pseudo-tendon" self-generating activity

Fig. A. Dog "pseudo-tendon" self-generated activity recorded with suspension ammeter. One end of the pseudo-tendon was clipped with tweezers and unidirectional electrical activity was recorded.Figure ${ }^{[2,3]}$. Fig. B. Assuming that there is no $\mathrm{Ca}^{2+}$ participation, the basic expectation of Fig. A using the inequality equation is applied. Fig. C. Conversion diagram explaining Fig.A.

The establishment of the $\mathrm{K}^{+}$channel "origami windmill"model ${ }^{[7]}$ has gone through the deduction process of practice-theory-re-practice-re-theory.Since 1994, the author has applied the transcranial electrical and transcranial magnetic electrical stimulation technology to invent a brain function rehabilitation therapeutic apparatus ${ }^{[8,9]}$ (1995), a 
depression therapeutic apparatus ${ }^{[10,11]}$ (2011), a Parkinson's disease therapeutic apparatus $^{[12,13]}$ (2011), Alzheimer's disease therapeutic apparatus ${ }^{[14,15]}$ (2014) and other encephalopathy rehabilitation treatment equipment are widely used in the clinical practice of cranial nerve diseases, and have achieved significant rehabilitation treatment effects. As the inventor, in order to clarify the treatment mechanism of equipment and the cause of severe cerebral disease, applying the principles of physical biology, "the theory of brain cell activation" ${ }^{[16]}$ (2015), "the theory of dove-like particles"[17] (2019), and “ $\mathrm{K}^{+}$channel 'origami windmill' model" ${ }^{\text {"1] }}$ (2019) was put forward from the level of cell molecule.

Applying the principle of the $\mathrm{K}^{+}$channel "origami windmill" model ${ }^{[18]}$, the whole process of the action potential generation mechanism of nerve fiber cells has been reasonably explained, and a view that is diametrically opposed to the ionic theory is obtained, that is, the action potential decline phase is caused by $\mathrm{K}^{+}$inflow Dominate (Figure 2). Although the mechanism of action potential generation of cardiomyocytes is much more complicated than that of nerve fiber cells, the principle of using the $\mathrm{K}^{+}$ channel "origami windmill" model can still give a scientific and reasonable explanation.

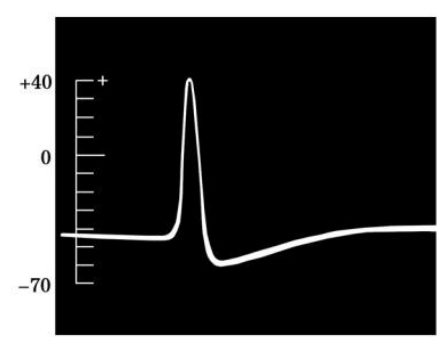

A

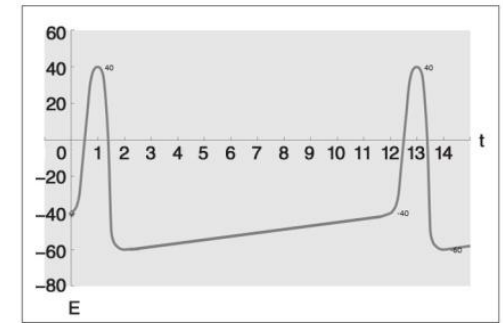

B

Figure 2 Intracellular recording of calamari giant axon action potential

Fig. A. The first intracellular action potential record ${ }^{[19]}$. Fig. B. Expectation or restore of resting potentials and action potentials using the unequal equation of ions.

\section{1. "Origami windmill" model}

The structure of the $\mathrm{K}^{+}$channel on the cell membrane is like the "origami windmill" model. Its working principle: the repulsive force formed by $\mathrm{K}^{+}$and other cations and the positively charged amino acid residues in the channel spiral pushes the "wind tooth" back and the "windmill" rotates, while the"windmill" the speed of rotation determines the "on" and "off" of the $\mathrm{K}^{+}$channel hole relative to $\mathrm{K}^{+}$. Its characteristic is that the four channel spirals form an independent functional unit. Simultaneous unidirectional rotation can "only in no out", and has no dependence on ATP. 
Based on the $\mathrm{K}^{+}$channel "origami windmill" model, it can be inferred that there are at least two types of channels on the cell membrane, one type of channel is the Enter (E) channel, and the structure is like the "origami windmill" model, each cell has at least one E channel; the other type of channel It is a Leave (L) channel. The structure only changes between the "on" and "off" conformations. It is passive and unidirectional, and can "only out no in". There is more than one L channel per cell. For two types of channels, relative to $\mathrm{K}^{+}$, the pore size is greater than or equal to the $\mathrm{K}^{+}$diameter when "open", and the pore size is smaller than the $\mathrm{K}^{+}$diameter but not smaller than the $\mathrm{Na}^{+}$diameter when "off". All ions or molecules entering and exiting the cell abide by the principle of "same direction sharing" of the channel.

The theoretical basis of the action potential of cardiomyocytes is the same as that of nerve fiber cells. The difference between cardiomyocyte action potential and nerve cell lies in that: in addition to $\mathrm{K}^{+}, \mathrm{Cl}^{-}$, and $\mathrm{Na}^{+}, \mathrm{Ca}^{2+}$ is also involved in the process of action potential generation in cardiomyocytes. $\mathrm{Ca}^{2+}$ inflow in the rising phase will shorten the depolarization time; $\mathrm{Ca}^{2+}$ inflow in the falling phase will prolong the repolarization time. $\mathrm{K}^{+}, \mathrm{Ca}^{2+}$ space substitution proportion: rotate into $2 \mathrm{~K}^{+}$, squeeze out $3 \mathrm{Ca}^{2+}$, and 4 extra negative charges in the cell, the proportion is 2: $3: 4$; Conversely, squeeze out $2 \mathrm{~K}^{+}$, rotate into $3 \mathrm{Ca}^{2+}, 4$ extra positive charges the cells, the proportion is 3: 2: $4 . \mathrm{Na}^{+}, \mathrm{Ca}^{2+}$ space substitution proportion: rotate into $1 \mathrm{Na}^{+}$, squeeze out $1 \mathrm{Ca}^{2+}$, and 1 extra negative charges in the cell, the proportion is $1: 1: 1$; Conversely, rotate into $1 \mathrm{Ca}^{2+}$, squeeze out $1 \mathrm{Na}^{+}$, there is 1 more positive charge in the cell, and the proportion is $1: 1: 1$.

$\mathrm{Na}^{+}$diameter (204pm) and $\mathrm{Ca}^{2+}$ diameter (200pm) are almost equal, and the proportion of substitution each other to $\mathrm{K}^{+}$(diameter $276 \mathrm{pm}$ ) is almost the same. However, the diameter of $\mathrm{Na}^{+}$is slightly larger than the diameter of $\mathrm{Ca}^{2+}$. This slight difference has a great influence on the action potential of cardiomyocytes, which determines that $\mathrm{Ca}^{2+}$ will flow out of cells before $\mathrm{Na}^{+}$.

\section{Cardiomyocyte action potential}

Cardiomyocytes, including ventricular myocytes, Purkinje cells, atrial myocytes, atrioventricular node cells, sinus node cells, etc. Among them, the action potential of ventricular myocytes is the most complex and typical ${ }^{[20,21]}$.

\subsection{Ventricular myocytes}

In a typical mammal, the ventricular myoelectric potential consists of the following five phases ${ }^{[22,23]}$ (Figure 1.C): phase 0 (rapid depolarization period, a-b-c-d), phase 1 (rapid repolarization zone, d-e), phase 2 (platform Period, e-f), 3 phases (repolar zone, f-g-h-i), 4 phases (rest zone, i-a). 


\subsubsection{Action potential 0 phase}

The rapid depolarization period, a-b-c-d. It rises from $-60 \mathrm{mV}$ to $0 \mathrm{mV}$ and then to $+50 \mathrm{mV}$ and then folds back to $+20 \mathrm{mV}$. The point a at $-60 \mathrm{mV}$ is the meta-point of the rising phase of the action potential and is also the threshold for triggering the action potential. The $\mathrm{L}$ channel of the cell is "open" with respect to $\mathrm{K}^{+}$, and the $\mathrm{K}^{+}$in the cell membrane escapes from the L channel out of the cell instantaneously, "windmill" The rotation speed increased, and the extracellular $\mathrm{Na}^{+}$and $\mathrm{Ca}^{2+}$ were quickly rotate into the intracellular $\mathrm{K}^{+}$position. The membrane potential instantaneously increased from the trigger potential $-60 \mathrm{mV}$ to the $+50 \mathrm{mV}$ c point, and finally stabilized at the $+20 \mathrm{mV} d$ point. The two sides of the membrane changed from the original "inner negative and outer positive" to "inner positive and outer negative" within a short period of time, forming the rising phase of the action potential. At position $0 \mathrm{mV}$ at point $b$, the positive and negative charges on the inner membrane of the cell are equal, that is, the sum of the number of positive charges carried by $\mathrm{Na}^{+}, \mathrm{Ca}^{2+}$, and $\mathrm{K}^{+}$is $310 \mathrm{G}\left(\mathrm{G}=1.25 \times 10^{3}\right)$, which is exactly the same as the number of $310 \mathrm{G} \mathrm{CL}^{-}$ pre-existenced in the cell; at point $\mathrm{c}+50 \mathrm{mV}$, the ions on the inner surface of the cell membrane are saturated, not only $\mathrm{Na}^{+}$, but also $\mathrm{Ca}^{2+}$; from point $\mathrm{c}$ of $+50 \mathrm{mV}$ to point $\mathrm{d}$ of $+20 \mathrm{mV}$, it is $\mathrm{Na}^{+}$that is rotate into the cell from the $\mathrm{E}$ channel The process of squeezing the intracellular $\mathrm{Ca}^{2+}$ from the $\mathrm{L}$ channel to the extracellular; at the $\mathrm{d}$ point of $+20 \mathrm{mV}$, the ions on the inner surface of the cell membrane are in a saturated state, all of which are $\mathrm{Na}^{+}$, the number is $330 \mathrm{G}$, and there should be no $\mathrm{K}^{+}$and $\mathrm{Ca}^{2+}$. Therefore, point $d$ can be understood as the true end of the rising phase.

The depolarization of ventricular myocytes is so fast, its rise is much steeper than that of nerve fiber cells, which is the result of the participation of $\mathrm{Ca}^{2+}$. The "overlapping" portion (c-d) that folds back from $+50 \mathrm{mV}$ to $+20 \mathrm{mV}$ is classified as an ascending phase dominated by $\mathrm{Na}^{+}$, because $\mathrm{Na}^{+}$rotate into the $\mathrm{E}$ channel "squeeze out" intracellular $\mathrm{Ca}^{2+}$ out of the cell, however $\mathrm{Ca}^{2+}$ only participates in and affects the action potential process, and should not be included in the descending phase dominated by $\mathrm{K}^{+}$inflow. Although $\mathrm{Ca}^{2+}$ in the $\mathrm{c}$-d segment does not play a role in the ultimate action potential, the amount of $\mathrm{Ca}^{2+}$ in and out of the cell can be estimated based on the "overlapping" part. There is a potential difference of $30 \mathrm{mV}$ from point $\mathrm{c}$ to point $\mathrm{d}$. $\mathrm{Ca}^{2+}$ is a divalent cation, so the amount of $\mathrm{Ca}^{2+}$ should be $15 \mathrm{G}$.

Action potential phase 0 is dominated by sodium ion influx, with $\mathrm{Ca}^{2+}$ influx and outflow participating.

\subsubsection{Action potential 1 phase}

Rapid repolarization zone, d-e. From $+20 \mathrm{mV}$ to $+10 \mathrm{mV}$. The $\mathrm{d}$ point of $+20 \mathrm{mV}$ is the real end point of the rising phase of the action potential and the meta point of the 
falling phase of the action potential. It can be understood here that the inner membrane of the cell has been completely replaced by $\mathrm{Na}^{+}$(ideal state). At this time, the $\mathrm{E}$ channel is relative to $\mathrm{K}^{+}$"Open”, the $\mathrm{K}^{+}$that the windmill spins in squeezes out the intracellular $\mathrm{Na}^{+}$. This process does not involve $\mathrm{Ca}^{2+}$, so it is called the fast repolarization zone.

Action potential 1 phase is dominated by $\mathrm{K}^{+}$inflow, and $\mathrm{Na}^{+}$outflow participates.

\subsubsection{Action potential 2 phase}

Repolarization platform period, e-f. At the e point of $+10 \mathrm{mV}$, extracellular $\mathrm{Ca}^{2+}$ and $\mathrm{K}^{+}$are rotated into the cell, and $\mathrm{Na}^{+}$is squeezed out the cell, the positive charges entry and exit of the e-f segment are equal, so a platform period appears, that is, the proportion of the amount of $\mathrm{K}^{+}, \mathrm{Ca}^{2+}$ rotated into the cell by the windmill and the amount of $\mathrm{Na}^{+}$squeezed out of the cell is $2: 1: 4$.

Action potential 2 phase is dominated by $\mathrm{K}^{+}$inflow, with $\mathrm{Ca}^{2+}$ inflow and $\mathrm{Na}^{+}$ outflow participating.

\subsubsection{Action potential 3 phase}

Repolarization zone, f-g-h-i $(+10 \mathrm{mV}$ to $0 \mathrm{mV}$ to $-60 \mathrm{mV}$ to $-90 \mathrm{mV})$. At the end of the platform period of $+10 \mathrm{mV}$ at point $\mathrm{f}$, there is still a small amount of $\mathrm{Ca}^{2+}$ rotated into by the windmill; at the position of $0 \mathrm{mV}$ at point $\mathrm{g}$, the positive and negative charges on the inner membrane of the cell are equal, that is, the sum of the number of positive charges carried by $\mathrm{Na}^{+}, \mathrm{Ca}^{2+}$, and $\mathrm{K}^{+}$is $310 \mathrm{G}$, which is exactly the same as the number of $310 \mathrm{G} \mathrm{CL}^{-}$pre-existenced in the cell. The position at $\mathrm{h}$ point $-60 \mathrm{mV}$ is different from the position at point a $-60 \mathrm{mV}$ in the ascending phase. The meaning and nature are different: the a point of the rising phase is that the cell membrane area is in an excessive saturated state, and $\mathrm{Na}^{+}$is rotated into the cell from the $\mathrm{E}$ channel causing the $\mathrm{L}$ channel to be relative to $\mathrm{K}^{+}$Open; the $\mathrm{h}$ point of the falling phase is that the surface ions in the cell membrane are in a saturated state. At the i point $-90 \mathrm{mV}$, the ions on the inner surface of the cell membrane are in a saturated state, all of which are $\mathrm{K}^{+}$, and the number is $220 \mathrm{G}$. At this time, there should be no $\mathrm{Na}^{+}$and $\mathrm{Ca}^{2+}$. Therefore, point i can be understood as the lowest point of the falling phase.

Action potential 3 phase is dominated by $\mathrm{K}^{+}$inflow, with $\mathrm{Ca}^{2+}$ inflow and outflow, $\mathrm{Na}^{+}$outflow participating.

\subsubsection{Action potential 4 phase}

The complete repolarization zone is also the resting zone, i-a. At the i point of $-90 \mathrm{mV}$, the $\mathrm{E}$ channel is "closed" relative to $\mathrm{K}^{+}$, but the windmill is still rotating, and extracellular $\mathrm{Na}^{+}$and $\mathrm{Ca}^{2+}$ are rotate into in the cell from the $\mathrm{E}$ channel again. In this process, the $\mathrm{Ca}^{2+}$ diameter is smaller than the $\mathrm{Na}^{+}$diameter, and the $\mathrm{Na}^{+}$rotated into from the $\mathrm{E}$ channel squeezes the intracellular $\mathrm{Ca}^{2+}$ from the $\mathrm{L}$ channel to the outside 
of the cell. At point a of $-60 \mathrm{mV}$, the cell is in an excessive saturated state, and the intracellular membrane has an additional 30G of $\mathrm{Na}^{+}$based on the existing $220 \mathrm{G}$ of $\mathrm{K}^{+}$. At this time, the action potential is triggered, and the $\mathrm{L}$ channel is "open" with respect to $\mathrm{K}^{+}$, the action potential Entered the next schedule.

Action potential 4 phase are dominated by $\mathrm{Na}^{+}$inflow, with $\mathrm{Ca}^{2+}$ inflow and outflow participating.

\subsection{Other cardiomyocytes}

The action potential of Purkinje cells (Purkinje fiber) is very similar to the action potential of ventricular muscle. The atrial muscle is similar to Pu's cells and very similar to cardiomyocytes. The action potentials of atrioventricular node cells and sinoatrial node cells are very similar, but they are very different from ventricular myocytes. From the figure, the rise is relatively slow, there is no peak at the highest point $\mathrm{c}$, and there is no Platform period ${ }^{[24]}$, the main reason : First, there is little participation of $\mathrm{Ca}^{2+}$, and second, the diameter of $\mathrm{Ca}^{2+}$ is slightly smaller than that of $\mathrm{Na}^{+}$, and there is leakage at any time during the depolarization process (Figure 3).

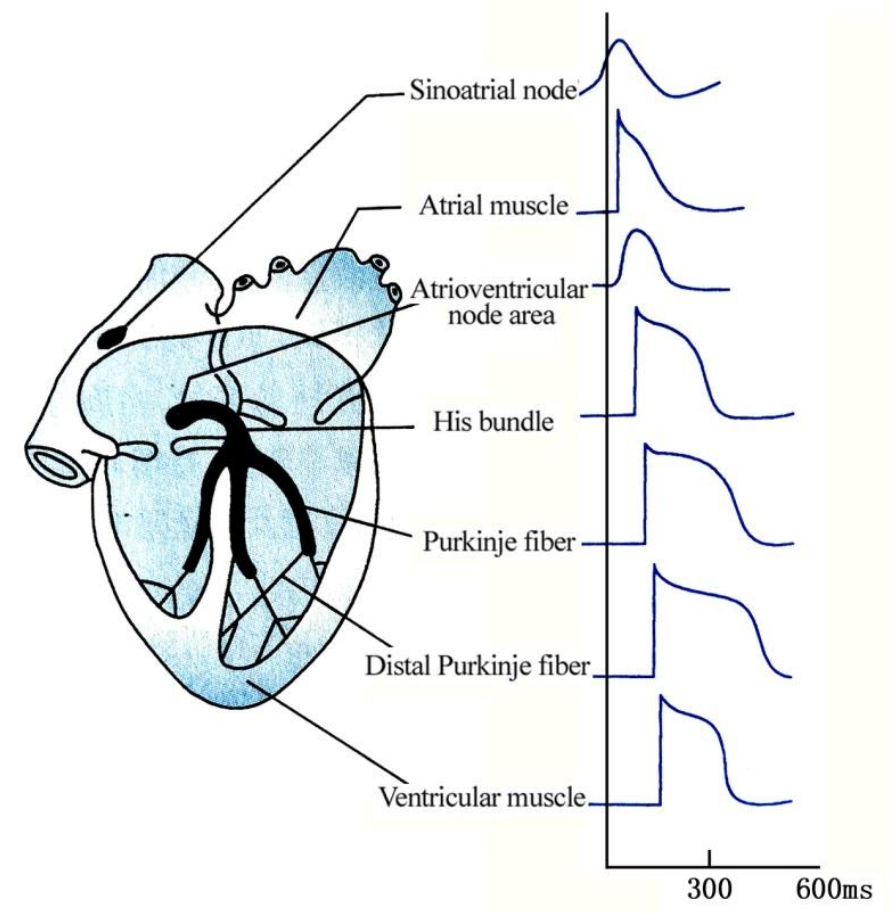

Figure 3 Action potentials of cardiomyocytes of various shapes

\section{Conclusion}

Application of "origami windmill" model principle, can reasonably explain the cardiomyocytes action potential generation mechanism, further proveding "origami windmill" the model theory, "the theory of dove-like particles" "the theory of braincell activation" of science, also proved that the viewpoint of "action potential descending phase, dominated by $\mathrm{K}^{+}$internal current" is correct. 
The study of the action potential of myocardial cells is as important as the study of nerve fiber cells, and it has become an indispensable basic knowledge and research method for understanding the physiology, pathology and pharmacology of cardiac activity. The scientific and rational interpretation of the action potential of myocardial cells has far-reaching impact and great significance to the basic theoretical research and clinical practice of the heart from now on.

It is necessary to explain that since 1994, the author of this article has been engaged in the research of basic theoretical research of brain science and the research and development of encephalopathy rehabilitation equipment,the tasks he has undertaken have been included in the national key new product plan project ${ }^{(1)}$, the national torch plan industrialization project $^{2}$, and the major scientific and technological breakthrough plan project in Heilongjiang ${ }^{(3)}$, he has won the first prize of Heilongjiang Science and Technology Award (invention category) ${ }^{(4)}$ and the first prize of Heilongjiang Excellent New Product ${ }^{(5)}$. He has won many national, provincial and municipal science and technology funds, including Heilongjiang Outstanding Youth Science Fund ${ }^{\circledR}$.The author himself is a technology leader of the leading talent echelon of "biomedical electronics" in Heilongjiang Province ${ }^{\curvearrowright}$, the head of Heilongjiang Provincial Brain Disease Rehabilitation Treatment Equipment Engineering Technology Research Center ${ }^{8}$, principal of National Postdoctoral research workstation $^{(9)}$, be selected for the national new century talents project ${ }^{(1)}$, enjoying special allowances of the State Council ${ }^{(11}$; Aobo Medical Founder, Dean of Ya'ou Brain Science Institute of Heilongjiang province. Founded in 2001, Ya'ou Brain Science Institute of Heilongjiang province is an independent legal entity and a professional academic research institution supported by Harbin Aobo Medical Devices Co., Ltd., focusing on basic theoretical research of brain science.

\footnotetext{
Note: (1)Transcranial magnetoelectric depression insomnia treatment instrument (project number: 2011TJB21022), Ministry of Science and Technology of China, 2011.(2)Transcranial Magnetoelectric Depressive Insomnia Treatment Instrument (Project No. 2012GH040294), Ministry of Science and Technology of China, 2012.(3) Development of tDCS Brain Function Rehabilitation Therapy Apparatus(Project No.: GC13C118), Certificate of Scientific and Technological Achievement Identification: Heikechengianzi [2016] No. 005. Transcranial magnetoelectric encephalopathy treatment instrument(Parkinson Therapeutic Apparatus) (Project Number: GB09C401), Scientific and Technological Achievement Appraisal Certificate: Heikechengjianzi [2011] No. 27, Development and Application of Transcranial Magnetoelectric Dementia Treatment Instrument (GC12C112), Heike Chengjianzi [2014] No. 34.(4)Heilongjiang Province Science and Technology Invention First Prize (Certificate Number: 2013030), Heilongjiang Provincial People's Government, 2013.(5) Transcranial magnetoelectric depression insomnia treatment instrument (Project No. 2011TJB21022), Heilongjiang Provincial Government, 2011. (6) National innovation fund project acceptance certificate, national innovation fund project approval certificate:Transcranialmagnetoelectric encephalopathy treatment instrument(Project code: 12C26212301482);The Heilongjiang Provincial Outstanding Youth Science Fund was awarded by the Heilongiang Provincial Natural Science Foundation in 2006.(7)Heilongiiang Provincial Department of Human Resources and Social Security, 2017; "Two butterflies" dancing in the spring of science, Science and Technology Daily, 2013-02-25. (8)Science and Technology Department of Heilongiiang Province, 2013. (9) Ministry of Human Resources and Social Security, 2013. (10Ministry of Personnel, Ministry of Science and Technology, etc., 2006; Three scholars from our province were selected into the second national "New Century Million Talent Project”, Heilongjiang Daily, 2006-12-07; (11) State Council, certificate number: 9230627, 2007.
} 


\section{References:}

[1]Burdon-Sanderson J, Page FJM. Notice of Further Experimental Researches on the Time-Relations of the Excitatory Process in the Ventricle of the Heart of the Frog. Proceedings of the Royal Society of London, 1879.

[2]Goldenberg M, Rothberger CJ. Arch Ges Physiol, 1936, 238: 137.

[3]Liu TF. Myocardial electrophysiology. Beijing: Peking University Press, 1988.

[4]Hecht HH, Woodbury LA, Woodbury JW, at al. Observations on the origin of the electrocardiogram: potential variations of single heart muscle fibers in situ. Journal of clinical investigation, 1950, 29(6):820-821.

[5]Weidmann $\mathrm{S}$. The effect of the cardiac membrane potential on the rapid availability of the sodium-carrying system. Journal of Physiology, 1955, 127: 213-224.

[6]Hodgkin AL, Katz B. The effect of sodium ions on the electrical activity of the giant axon of the squid. J Physiol, 1949, 108:37-77.

[7]Sun ZD. Potassium Channel Origami Windmill Model. Journal of US-China Medical Science, 2019, 16(4): 1-4.

[8]Jiao MD, Sun ZD. Effects of Aobo brain function rehabilitation instrument on cerebral circulation and brain function. Medicine Healthcare Apparatus, 1998, 3: 251-52.

[9]Tian NN. Application of Aobo brain function rehabilitation instrument in post-troke hemiplegia patients. Chinese Journal of Medical Device, 2009, 9:68.

[10]Harbin Successfully Develops the First Therapeutic Instrument for Depression in the World. Science-Technology\& Publication, 2011, 6: 127.

[11]Zou W, Tang Q, Sun ZD, et al.Clinical Study on Transc-ranial Magnetoelectric Depression Treatment Instrument Treatmenting Depression. viXra.org, viXra:1707.0026, 2017-07-04.

[12]Xing XL, Tang Q. Clinical research on influences of transcranial magnetoelectric stimulation on Parkinson's disease.(The assembly of conference papers of the 11th national rehabilitation academic conference of Exercise Therapy Branch of Chinese Association of Rehabilitation Medicine, 2011).

[13]Tang Q, Zou W, Sun ZD, et al. Clinical study on Transcranial magnetoelectric encephalopathy treatment instrument treatmenting parkinson's disease. Beijng: Sciencepaper Online[2017-02-08]. http://www.paper.edu.cn/releasepaper/content/201702-38.

[14]Tang Q, Zou W, Sun ZD, et al. Clinical study on transcranial magnetoelectric encephalopathy treatment instrument for Alzheimer's disease. Highlights of Sciencepaper Online, 2017, 10(11): 1216-1222.

[15]Successful development of the first therapeutic instrument for Alzheimer disease in the world. Science Technology \& Publication, 2014, 6: 143.

[16]Sun ZD. The Theory of Brain Cell Activation. Journal of US-China Medical Science, 2017, 14(5): 203-211.

[17]Sun ZD. The Theory of Dove-like Particles. Journal of US-China Medical Science, 2019, 16(2): 73-99.

[18]Sun ZD. Interpretation of Action Potential Generation Mechanism in Cells by Potassium Channel "Origami Windmill” Model. Journal of US-China Medical Science, 2019, 16(4): 1-7.

[19]Hodgkin AL, Huxley AF. Action Potentials Recorded from Inside a Nerve Fibre. Nature, 1939, 144(3651):710-711.

[20]Liu TF. Cardiomyocyte electrophysiology. Beijing: Peking University Press, 2000. 
[21]Cranefield PF. Action potentials, afterpotentials, and arrhythmias. Circulation Research, 1977, 41(4): 415-423.

[22]Liu TP, Chen XJ. Characteristics of depolarization of mouse atrium after early onset. Science China Press(B,Chemistry, Life Science), 1993(1):26-31.

[23]Hume JR , Uehara A, Hadley RW, et al. Comparison of $\mathrm{K}^{+}$channels in mammalian atrial and ventricular myocytes. Progress in clinical and biological research, 1990, 334:17-41.

[24]Wang TK. Physiology. 9th ed. Beijing: People's Medical Publishing House, 2018, 98-112. 